\title{
A COMPARATIVE STUDY USING INTERRUPTED FIGURE OF EIGHT SUTURE VERSUS CONVENTIONAL CONTINUOUS SUTURING FOR CLOSURE OF EMERGENCY MIDLINE LAPAROTOMY
}

\section{DR RAJASHEKARA BABU $\mathbf{G}^{1}$, DR AKHILA $\mathbf{N}^{\mathbf{2}^{2 *}} \&$ DR SUBHASHINI RAO}

${ }^{I}$ Professor, Department of General Surgery, Bangalore Medical College and Research Institute, Bangalore, Karnataka, India

${ }^{2}$ Senior Resident, Department of General Surgery, Bangalore Medical College and Research Institute, Bangalore, Karnataka, India

${ }^{3}$ Post Graduate, Department of General Surgery, Bangalore Medical College and Research Institute, Bangalore, Karnataka, India

\section{ABSTRACT}

Introduction

Wound infections continue to represent a major medical problem, both in terms of how theyaffect the outcome of surgical procedures (surgical site infections), and for their impact on the length of hospital stay and medical costs.Many otherwise successful surgical operations fail because of the development of wound infections.

A major SSI is defined as a wound that either discharges significant quantities of pus spontaneously or needs a secondary procedure to drain it. Wound infection predisposes the patient to wound dehiscence. Acute wound failure is defined as postoperative separation of the abdominal musculoaponeurotic layers, within 30 days after operation. Most surgical wound infections become apparent within 7 to 10 days postoperatively.

Objectives of the study:

1. To assess local wound complication in emergency midline laparotomy woundswith interrupted figure of eight technique over conventional continuousclosure.

2. To Compare the operative time for interrupted figure of eight closure andconventional layered closure of laparotomy wounds.

3. To determine the factors affecting wound dehiscence.

Materials and Methods: A prospective study was performed at Victoria hospital and Bowring and Lady Curzon hospital , Bangalore during November 2017 - May 2019. A sample of 100 cases were considered. Each Group consisted of 50. Group 1 underwent Interrupted figure of Eight suture technique and Group 2 underwent continuous conventional suturing technique.

Results: The incidence of burst abdomen in current study was $8 \%$. There were two burst abdomens seen in conventional continuous closure technique and none in the interrupted figure of eight technique group.

Interpretation and conclusion: All the patients with generalized peritonitis in emergency setting need special attention regarding the wound closure. This newer technique of midline emergency laparotomy wound closure, especially in our part of the world significantly reduces the incidence of wound infection and wound dehiscence.

KEYWORDS: Wound dehiscence, burst abdomen, interrupted Vs. continuous suturing

Received: Aug 08, 2020; Accepted: Aug 28, 2020; Published: Oct 07, 2020; Paper Id.: IJMPSAUG20207 


\section{INTRODUCTION}

Wound dehiscence is described as partial or complete disruption ofan abdominal wound closure with or without protrusionand evisceration of abdominal contents ${ }^{[1]}$ It refers to postoperative separation of the abdominal musculo aponeurotic layers. ${ }^{[2]}$ It is among the most dreaded complications faced by surgeons and is of great concern because of the risk of evisceration, the need for some form of intervention, and the possibility of repeat dehiscence, surgical wound infection, and incisional hernia formation. ${ }^{[3]}$ Incidence of wound dehiscence is about $1-3 \%$ in patients undergoing laparotomy. Dehiscence most often develops 7 to 10 days postoperatively.

A multitude of factors may contribute to wound dehiscence namely $y^{[4]}$

Technical error in fascial closure, Emergency surgery, Intra-abdominal infection, Advanced age

Wound infection, hematoma, and seroma, Elevated intra-abdominal pressure

Obesity, Chronic corticosteroid use, Previous wound dehiscence, Malnutrition

Radiation therapy and chemotherapy, Systemic disease (uremia, diabetes mellitus).

Acute wound failure may occur without warning and evisceration makes thediagnosis obvious . Clinically copious amount of a clear, salmon collared fluidprecedes dehiscence in $25 \%$ of patients. More often, patients report a ripping sensation. Probing the wound with a sterile, cotton-tipped applicator or gloved finger may detect a partial dehiscence. Hence, appropriate measure need to be taken while closure of the laparotomy wound such as proper spacing of suture, adequate depth of the bite of fascia, achieving tension free closure.For very high-risk patients, interrupted closure is often the wisest choice. Alternative methods of closure must be selected when primary closure is not possible without undue tension.

\section{OBJECTIVES}

- To assess local wound complication in emergency midline laparotomy wounds with interrupted figure of eight technique over conventional continuous closure .

- To Compare the operative time for interrupted figure of eight closure and Conventional layered closure of laparotomy wounds.

- To determine the factors affecting wound dehiscence 


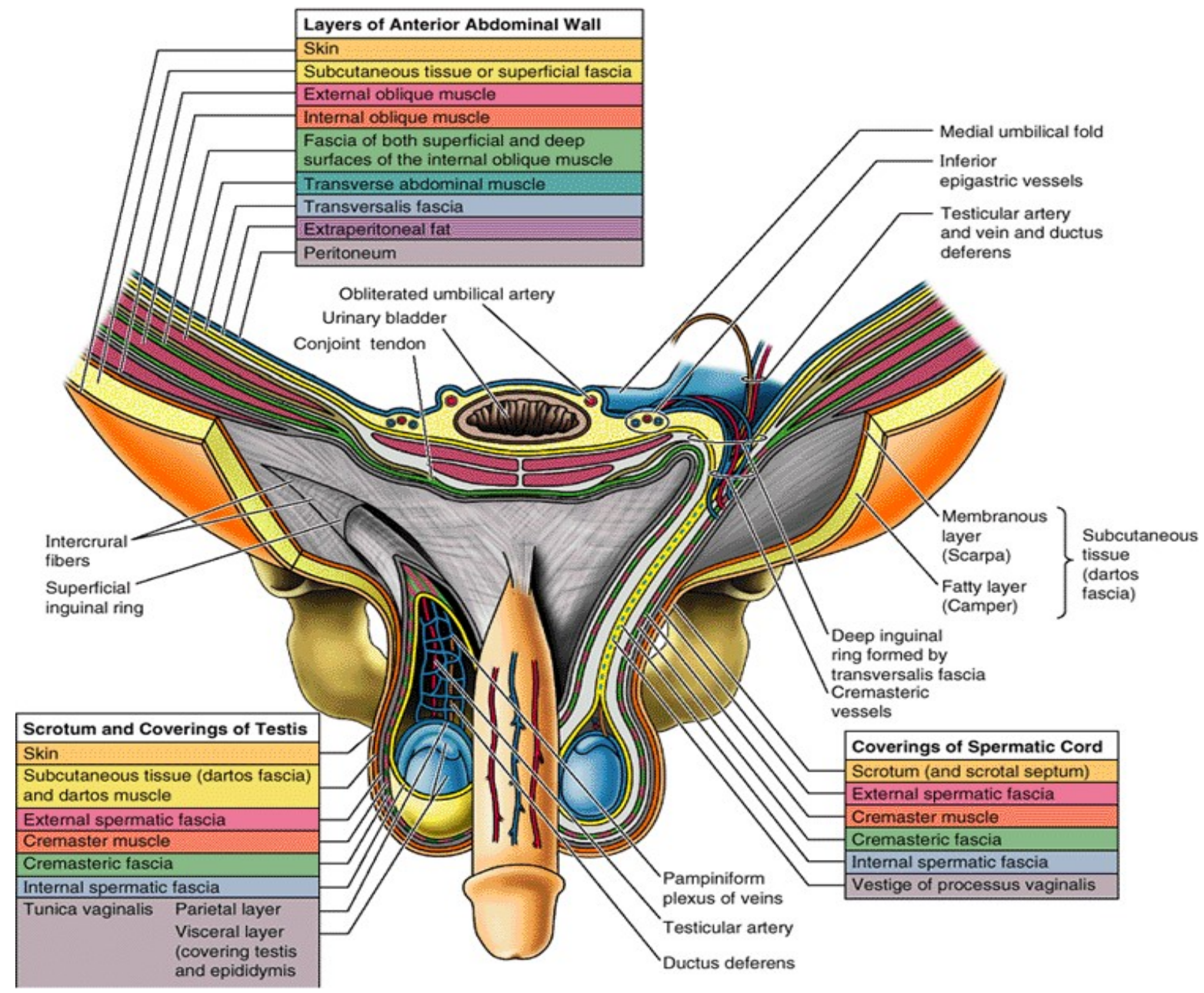

Figure 1: Layers Of Anterior Abdominal Wall.

\section{MATERIALS AND METHODS}

Study Design: Prospective.

Study period : November 2017 - May 2019.

Study Area: Victoria hospital and Bowring and Lady Curzon hospital, Bangalore.

Sample Size: 100 cases.

\section{Inclusion Criteria:}

All adult patients giving consent to undergo a midline laparotomy for emergency reasons (hollow viscus perforation, stab injuries, blunt trauma abdomen).

\section{Exclusion Criteria:}

Severe co-morbid conditions such as severe renal and liver disease,

Severe anaemia, uncontrolled diabetes, malignancy,

Patient on anticancer chemotherapy or steroids, previous laparotomy. 
Age $<18$ yrs

Primary peritonitis.

Patients not giving consent.

Patients on cancer chemotherapy, immunotherapy and on long term steroids.

Patient who has undergone previous laparotomy for any condition ( or had an incisional hernia or burst abdomen at presentation.)

\section{Procedure:}

After taking permission from Ethical Committee clearance, all patients wereexplained about the study in their own understandable language and then written consent with sign was taken. They are randomized to undergo either conventional closure or interrupted figure of eight technique using simple random sampling.

A)Conventional closure: is performed using No. 1 prolene suture (polypropylene) care being taken to place each bite 1.5$2 \mathrm{~cm}$ from the linea alba edge and successive bites being $1 \mathrm{~cm}$ from each other. The edges of the linea alba were gently approximated without strangulation with an attempt to keep a suture to wound length ratio of 4:1. Each suture is placed at 2 cm interval. Subcutaneous tissue closed with interrupted vicryl 2-0. Skin sutured separately with nylon 2-0.

B) Interrupted figure of Eight: It was performed using No. 1 Prolene suture. A large bite was taken on the cut edge of linea alba from outside-in, $2 \mathrm{~cm}$ from edge. The needle emerged on the other side from inside-out diagonally $2 \mathrm{~cm}$ from the edge and $4 \mathrm{~cm}$ above or below the first bite. This strand was crossed or looped around the free end of suture and continued outside-in, diagonally at 90 to the first diagonal. The two ends were tied just tight enough to approximate the edges of linea alba taking care not to include bowel or greater omentum between the edges. The small free end of the suture was passed deep to the $\mathrm{X}$ behind linea alba and again tied to the other end of the suture. This method of tying four throws in front and four throws behind the X created two X-like crosses - one on the surface and another deep to linea alba. The central knot allowed fixation of four arms of the X like a pivot. The next X-suture was placed $1 \mathrm{~cm}$ away (above or below) from the previous one. Thus, in a $14 \mathrm{~cm}$ long wound, $3 \mathrm{X}$-sutures were applied. The suture line was then palpated for any gap with the index finger. Any large gap permitting a finger was closed with a simple interrupted suture.

Each patient is followed for 6 weeks after surgery to determine post-operative

Complications like wound infections, partial or complete wound dehiscence.

Wound is inspected for the presence of infection like purulent discharge or redness. Wound dehiscence is considered when intestine, omentum or other viscera are seen in the abdominal wound.

At end of study data was entered in MS Excel sheet and analysed in SPSS software with 20.0 version. 
(a)

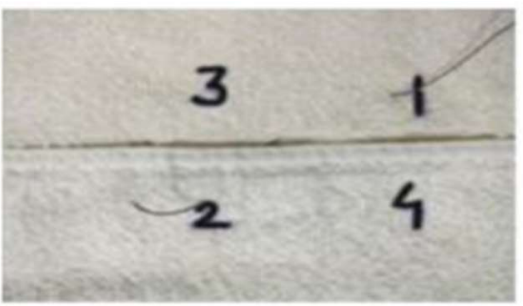

(c)

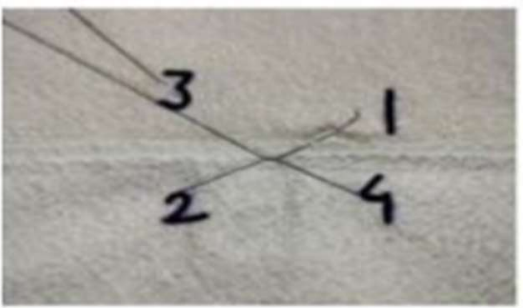

(e)

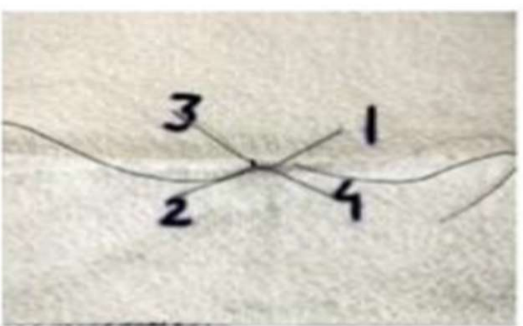

(b)

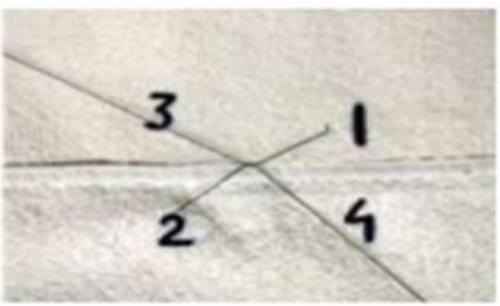

(d)

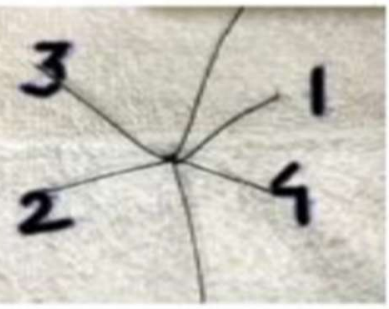

$(f)$

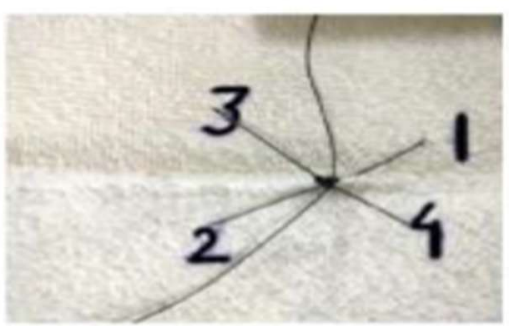

Figure 2: Interrupted Figure Of Eight Technique

\section{RESULTS}

\section{Age Distribution}

The total number of cases studied was 100 . This study depicted that the maximum no. of patients where in $6^{\text {th }}$ decade of life

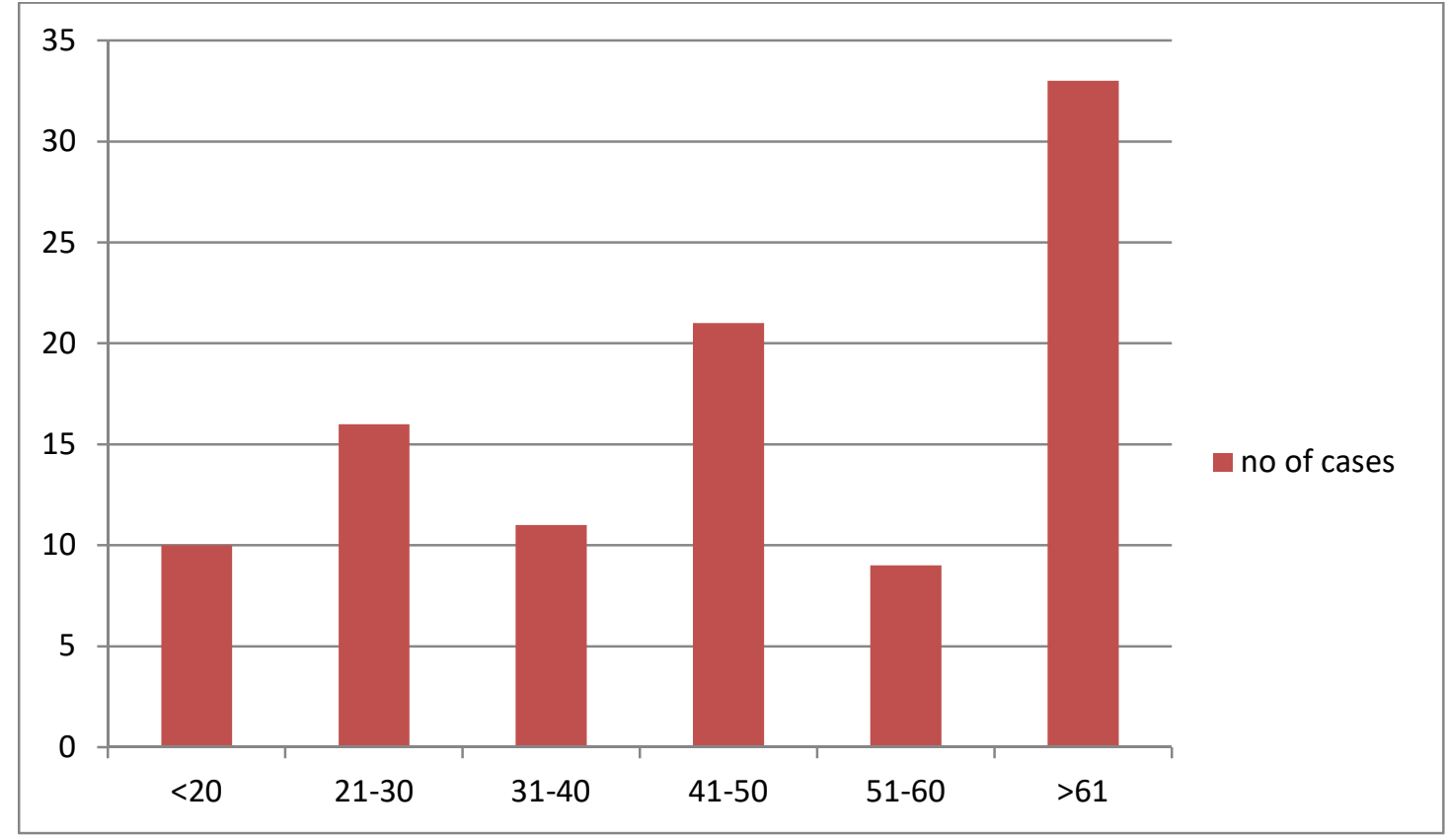

Graph 1: Age Distribution 
Table 2: Age Distribution

\begin{tabular}{|c|c|c|}
\hline Age in Years & No of Cases & Percentage \\
\hline$<20$ & 10 & 10 \\
\hline $21-30$ & 16 & 16 \\
\hline $31-40$ & 11 & 21 \\
\hline $41-50$ & 21 & 09 \\
\hline $51-60$ & 09 & 33 \\
\hline$>61$ & 33 & \\
\hline
\end{tabular}

\section{Sex Distribution:}

In a total of 100 cases, 25 patients were female and 75 were males.

Table 3: Sex Distribution

\begin{tabular}{|l|c|c|}
\hline \multicolumn{1}{|c|}{ Sex } & No of Patients & Percentage \\
\hline Male & 75 & 75 \\
\hline Female & 25 & 25 \\
\hline
\end{tabular}

\section{Number of burst Abdomen:}

In the group 1 ( Interrupted Figure of Eight Technique), there were no burst abdomen and in group 2 ( Conventional technique), there were 4 burst abdomen cases.

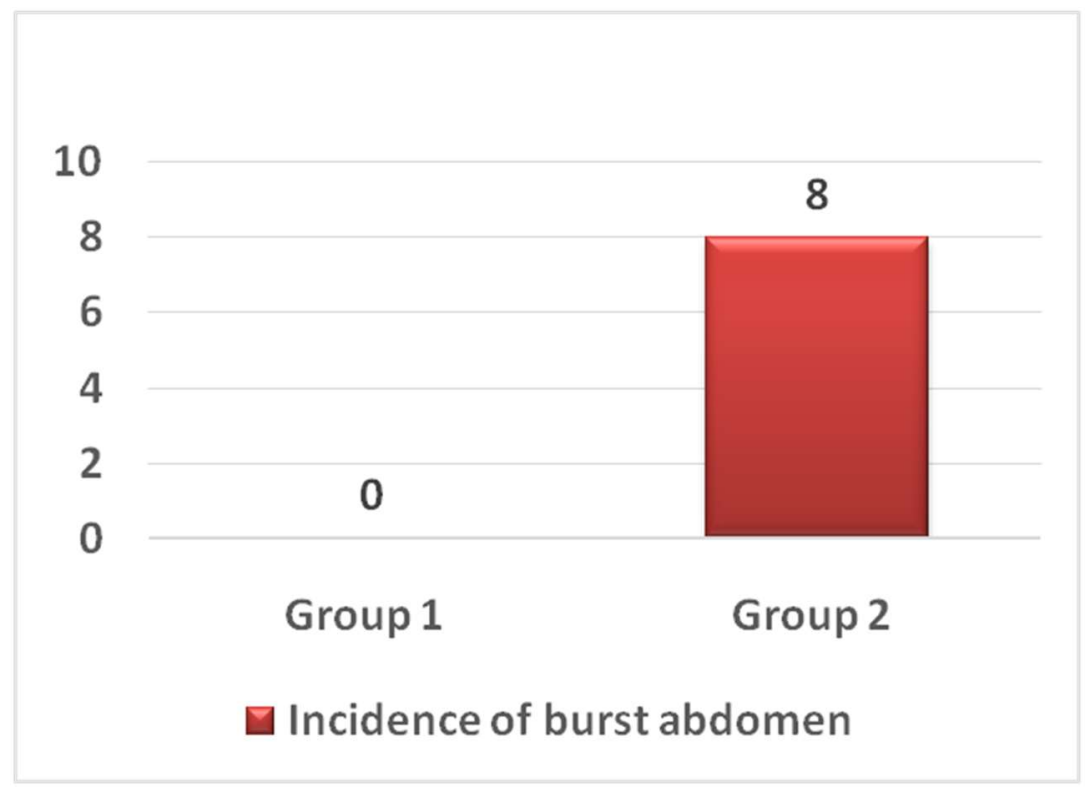

\section{Graph 2: Incidence of burst Abdomen}

\section{Incisional Hernia (IH):}

In the group 1 ( Interrupted Figure of Eight Technique), there was 1 case of incisional hernia and in group 2 ( Conventional technique), there were 5 cases. 


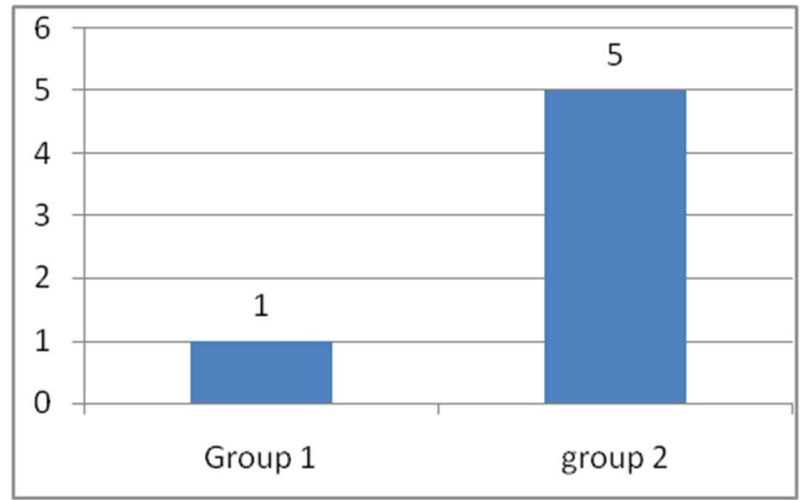

Graph 3: Incidence of Incisional Hernia

Table 4: Analysis of Risk factors

\begin{tabular}{|c|c|c|c|c|c|c|c|}
\hline Risk Factor & & ients With & & & nts Witho & & 'P' Value \\
\hline & Group 1 & Group 2 & Total & Group 1 & Group 2 & Total & \\
\hline Anaemia & 14 & 04 & 28 & 36 & 46 & 82 & 0.009 \\
\hline Elderly & 23 & 14 & 37 & 27 & 36 & 63 & 0.062 \\
\hline Uraemia & 20 & 25 & 45 & 30 & 25 & 55 & 0.315 \\
\hline $\begin{array}{l}\text { Hypoalbumi- } \\
\text { nemia }\end{array}$ & 31 & 16 & 47 & 19 & 34 & 53 & 0.003 \\
\hline Jaundice & 04 & 03 & 07 & 46 & 47 & 93 & 0.695 \\
\hline
\end{tabular}




\begin{tabular}{|c|c|c|c|c|c|c|c|}
\hline $\begin{array}{c}\text { Peritoneal } \\
\text { Contaminati- } \\
\text { on }\end{array}$ & 25 & 27 & 52 & 25 & 23 & 48 & 0.689 \\
\hline SSI & 16 & 21 & 37 & 34 & 29 & 63 & 0.300 \\
\hline Cough & 19 & 20 & 39 & 31 & 30 & 61 & 0.838 \\
\hline Post op ileus & 28 & 24 & 52 & 22 & 26 & 48 & 0.423 \\
\hline Obesity & 7 & 10 & 17 & 43 & 40 & 83 & 0.424 \\
\hline Diabetes & 22 & 06 & 28 & 28 & 44 & 72 & 0.001 \\
\hline
\end{tabular}

' $\mathrm{P}$ ' Value $<0.05$ is statistically significant.

\section{DISCUSSIONS}

Acute wound failure has been discussed under various names i.e. wound dehiscence, burst abdomen, wound disruption and evisceration. It is a very serious complication of abdominal surgery, with very high mortality rate and no single cause being responsible, rather it is a multi-factorial problem. Two basic events are seen in wound dehiscence are decreased wound strength and increased collagenolysis, most commonly due to infection. ${ }^{[23,23,25]}$ The ideal fascial closure should maintain tensile strength throughout the healing process. The dynamic process of wound healing can be divided into three phases. The first exudative phase (days 1-4) does not provide any holding strength to the wound. It is followed by the proliferative phase (Days 5-20), in which the tissue regains approximately $15-30 \%$ while up to $80 \%$ of its original tensile strength is regained in the third or remodelling phase (days 21 onwards). It was demonstrated in the early 1950s that the healing process of abdominal fascia after surgical incision continues for 9 to 12 months. Abdominal fascia regains only $51 \%$ to $59 \%$ of its original tensile strength at 42 days, $70 \%$ to $80 \%$ at 120 days, and $73 \%$ to $93 \%$ by 140 days.[26] A sutured wound bursts because either the suture breaks or its knot slips or it cuts through the tissues. Generally the first 2 reasons are rare, and wound dehiscence occurs when the suture material tears through the fascia. The strength of a particular suture material increase as its cross-sectional diameter increases and smaller diameter sutures are associated with a greater likelihood of tearing through the tissue. ${ }^{[27,28]}$ 
It has been shown experimentally by Jenkins that the length of a midline laparotomy incision can increase up to $30 \%$ in the postoperative period in association with several factors that increase the intra-abdominal pressure and determined that a suture length to wound length ratio should be 4:1. ${ }^{[29]}$ A meta-analysis on 23 randomized trials showed that odds of burst are reduced to half with interrupted method of closure compared to continuous method. [29] In emergency surgery, interrupted sutures are better than continuous method as they have "gigli saw" or "hack saw" effect.[30] Various types of interrupted sutures are described. They are Smead- Jones far and near technique, figure of eight, Hughes technique of double far and near horizontal mattress and the latest interrupted X suture by Srivastava A et al. Bucknall et al .31 prospectively studied 1129 abdominal operations and demonstrated that layered closure was associated with a significantly higher dehiscence rate compared with mass closure (3.81\% vs. $0.76 \%)$. Similarly other studies have also shown that mass closure have low incidence of wound dehiscence and incisional hernia. ${ }^{[30,31]}$

\section{CONCLUSIONS}

The most significant risk factors contributing the development of post-operative abdominal wound dehiscence:

- Old age, male sex, anaemia, malnutrition, obesity, peritonitis, emergency surgery, perforation closure, resection and anastomosis.

- Midline incisions, poor suture technique, surgeons experience and adherence to improper aseptic precautions with potential wound infection followed by abdominal wound dehiscence.

- Preventive measures are prophylactic optimization of patients' comorbid conditions, improving the nutritional status of the patient, proper aseptic precautions, optimising patients' lung condition, avoiding other straining conditions like cough and by applying proper surgical technique with adequate skill acquisition.

- Management of abdominal wound dehiscence needs sincere attention by the treating surgeon on early identification wound dehiscence and effective application of debridement techniques followed by proper suturing techniques. Further studies to investigate management of wound dehiscence and innovative techniques like VAC therapy need to be done.

- In a continuous suturing cutting out of even a single bite of tissue leads to opening of the entire wound. This is the probable explanation for a high prevalence of burst in our conventional group.

- Presently use of retention sutures is controversial. Hughes far and nearsutures or Smead-Jones sutures are said to be better. However retention sutures are used wide worldwide even now.

- Further studies are recommended on a large scale of patients to evaluate the effectiveness of the technique or possible modifications of it.

- In conclusion, interrupted figure of eight suturing reduces the occurrence of burst abdomen in high risk case.

\section{REFERENCES}

1. F. Charles Brunicardi, Dana K. Andersen, Timothy R. Billiar, David L. Dunn, JohnG. Hunter, Jeffrey B. Matthews, et al. SCHWARTZ'S PRINCIPLES OF SURGERY,9TH EDITION, 2010.

2. R. M. Kirk, Richard Novell, Daryll Baker, Nicholas Goddard, Kirk’s GeneralSurgical Operations, 6th Edition, 2013. 
3. Debbarma, Shibajee, et al. "Epidemiology of Accident Cases Attending a Tertiary Care Hospital in Kanpur." International Journal of Medicine and Pharmaceutical Sciences (IJMPS) 6.1 (2016): 125-130.

4. Robert Bendavid, Jack Abrahamson, Mourice E. Arregui, Jean Bernard Flament,Edward H. Philips, Abdominal Wall Hernia; Principles and Management, 2001.

5. Jones T E, Newelle E T, Brubaker R E, The use of alloy steel wire in closureof the abdominal wounds. SurgGynaecolObstet 1941;72:1056-9.

6. Kumar, Navneet, TanuMidha, and Yashwant Kumar Rao. "Determinants of Epilepsy in Children and Adolescents (6-19 Years) in a Tertiary Care Hospital in Kanpur." International Journal of Medicine and Pharmaceutical Science (IJMPS) 8.1 (2018): 53-58.

7. Fagniez PL, Hay JM, Lacàine F, Thomsen C. Abdominal midline incisionclosure. A multicentric randomized prospective trial of 3,135 patients, comparing continuous vs interrupted polyglycolic acid sutures. Arch Surg1985;120:1351-3.

8. Agarwal, Vikas, et al. "Clinical profile of headache from a tertiary care center in eastern India." International journal of general medicine and pharmacy (IJGMP) 2.3 (2013): 9-14.

9. Srivastava A, Roy S, Sahay KB, Chumber S, Seenu V, Kumar A, et al. Prevention of burst abdomen by a new technique: A randomizedtrial comparing continuous versus interrupted x-suture. Indian J Surg2004;66:19-27.

10. Kumar P, Chaubey D, Sahu SS, Shashi K, Mundu M, Baxla RJ. Comparative Studyof Continuous versus Interrupted X Type Abdominal Fascial Closure in Reference toBurst Abdomen. Int J Sci Stud 2014;2(7):10-16

11. Velhal, G. D., et al. "Awareness among nursing staff about roles and responsibilities in a tertiary level health care institute, India." International Journal of General Medicine and Pharmacy (IJGMP) 2.2 (2013): 75-80.

12. Makela JT, Kiviniemi H, Juvonen T. Factors influencing wound dehiscence aftermidline laparotomy. Am J Surg 1995:; 170:387-90

13. Van"t Riet M, Steyerberg EW, Nellensteyn J, Bonjer HJ, Jeekel J (2002)Meta-analysis of techniques for closure of midlineabdominal incisions. Br J Surg 89(11):1350-1356

14. Larsen W.J., Human Embryology, edited by Strauss Marc, 2nd edition, NewYork, Churchill Livingstone, 1997;203.

\section{CLINICAL PHOTOGRAPHS}

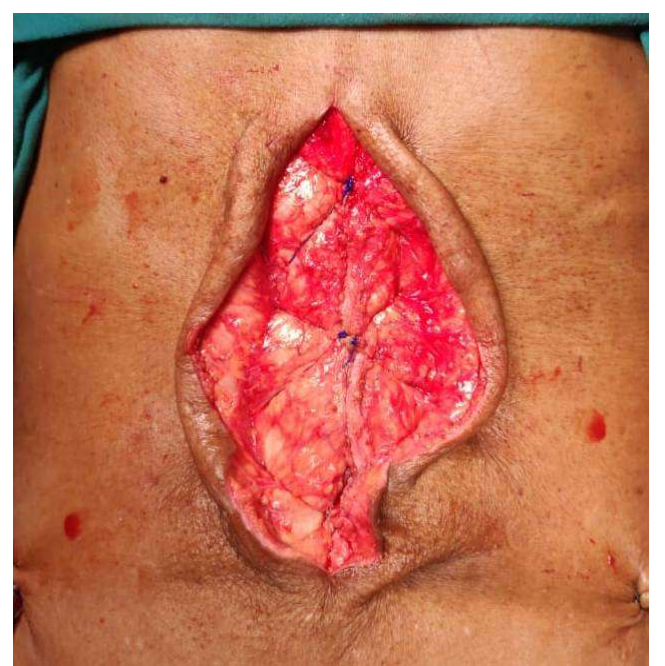

Figure3: Interuupted Figure of Eight Technique 